\title{
Research on the Modeling Design of Modern Tea Wares
}

\author{
Yueming $\mathrm{He}^{1, *}$ \\ ${ }^{1}$ Xiamen Academy of Arts and Design, Fuzhou University, Xiamen, Fujian 361021, China \\ *Corresponding author. Email: tommyqhg@163.com
}

\begin{abstract}
China's tea culture is an indirect expression of humanistic thought and geological culture. In the era of world integration, China's tea culture is also loved by people all over the world. Tea ware modeling is an important part of tea culture. In order to meet the aesthetic needs and tea drinking needs of modern people, modern tea ware modeling also began to show a diversified development trend, integrating many popular modern ideological elements, making modern tea ware modeling have more Chinese cultural connotation. Starting from the positive connotation of modern tea ware modeling in the era of education, this paper expounds the design principles and design direction of modern tea ware modeling, so as to open up the practical path of modern tea ware modeling with innovative ideas and carry forward China's modern tea culture.
\end{abstract}

Keywords: Modern tea ware, Modeling design, Aesthetic needs, Tea culture.

\section{INTRODUCTION}

As an ancient Chinese saying goes, "it is suggested to cultivate morality by means of simplicity and calmness." This is a general description of the cultural thought of ancient Chinese tea, which runs through the development history of ancient and modern China. Literati drink the tea. Tea has become an indirect symbol of life situation and quality of life. Chinese people's love for tea also means that they love their own life. Offering tea to guests, giving tea to the young and substituting tea for wine are all forms of tea culture. The process of drinking tea seems simple, but contains rich philosophy of life. The fragrance of tea brings people a high sense of physical and mental pleasure and aesthetic experience. And part of this aesthetic experience also comes from the modeling of tea utensils. In China's vast land, the modelings of tea wares are diversified and threedimensional due to geological, material, cultural and other factors. Tea wares of different shapes can meet people's different tea drinking and aesthetic needs. With the continuous development of science, culture and technology, modern tea modeling is

*Fund: Research on the modeling design of ceramic tea ware from the contemporary perspective, project number: 0170511008 . also changing with the times. More modern popular ideas begin to be used into tea modeling, which inject fresh vitality into its development. On the road of adhering to the Chinese dream, it is suggested to follow the cultural development strategy of going out. The innovative development of tea culture also enables it to be popular with people all over the world, which improves China's cultural output efficiency and cultural selfconfidence. However, from the fast-paced life of people in modern society, the positive benefits brought by drinking tea are constantly weakening. Starting from the modeling design of modern tea ware, it is necessary to integrate more innovative design ideas into it to enrich the spiritual needs and aesthetic experience brought by tea culture.

\section{THE POSITIVE CONNOTATION OF THE MODELING DESIGN OF MODERN TEA WARES IN THE EDUCATION AGE}

Under the positive guidance of the era of education 4.0, cultivating high-quality talents with simultaneous development of five disciplines has become the current development goal of schools at all levels, and tea culture education is also one of the components of students' moral education and 
aesthetic education. At the same time, it is also an educational way to cultivate students' core qualities such as aesthetic ability, innovative design ability and cultural self-confidence. According to the educational goal of the new curriculum reform, the traditional examination-oriented education thought is constantly weakened, and students can achieve the original intention of education. In the process of students learning the modeling design of modern tea wares, they can experience the social philosophy of the joy of human relations contained in Chinese tea culture imperceptibly, enrich their social ability and correctly understand the positive significance of education [1]. In the teaching process of modern tea ware modeling design, students need to have a certain understanding of tea culture, modern product design concept and innovative modeling design. Therefore, learning modern tea ware modeling design would help improve students' comprehensive application and practical ability [2]. As time goes by, Chinese tea culture has developed a variety of educational contents such as tea art, tea technology, tea morality and tea etiquette, realizing a demand leap from material demand to spiritual demand. Modern tea ware modeling design also requires students to have a certain understanding of tea art, tea technology, tea morality and tea etiquette. In this process, students will have a deeper understanding of traditional culture and life.

\section{THE DEVELOPMENT HISTORY OF TEA WARE MODELING}

In order to achieve the result of "excelling one's master", modern tea ware modeling designers need to deeply understand the development history of Chinese tea ware modeling [3]. Before the Tang Dynasty, China did not form a conceptual and specific tea ware modeling culture. Tea shared the same utensils with wine and water. Although its utensils were exquisite, they did not contain any tea culture. After the Tang Dynasty (including the Tang Dynasty), with the rise of poetry culture, it also led to the development of tea culture. Because different tea needs different tea cooking methods, there are tea wares of different functions, materials and shapes. In addition, 28 kinds of tea wares were described in the "tea classic" written by $\mathrm{Lu} \mathrm{Yu}$, which showed the prosperity of tea ware modeling at that time [4]. The softness of Song Poems is similar to tea etiquette. Although there was no innovative breakthrough in the basic modeling of tea wares in the Tang Dynasty at that time, the people found their own ways to enrich the humanistic spirit and aesthetic experience of tea wares from the modeling color, material and drinking customs. Under the rule of the nomadic nationalities in the Yuan Dynasty, the modeling development of tea wares and even the whole tea culture encountered a Waterloo for the first time. On the one hand, the loose tea brewed and drunk replaced the tea cakes with beautiful shapes, which also led to many tea wares designed based on tea cakes slowly stepping down the historical stage [5]. In the Ming Dynasty, the brew method was used to bake strip loose tea. Although the operation was simple and convenient, it limited the development of some boiling tea wares. There was no innovation in the modeling of tea ware in the Qing Dynasty. It still focused on tea lamps and teapots, but enriched the external appearance of tea ware modeling from the perspective of material and modeling [6]. Most modern tea wares inherit the modeling of the tea wares in Ming Dynasty, and add some modern popular elements to make them more innovative.

\section{THE NEW DESIGN PRINCIPLES OF MODERN TEA WARE MODELING}

\subsection{Improving the Rational Structure Influence of Modern Tea Ware Modeling}

With the changes of users' needs, designers of modern tea ware modeling constantly innovate their own design principles, and the first step in the development of innovative design of tea ware modeling is to improve the rational structural influence of modern tea ware modeling. The rational structure of tea ware modeling includes four aspects: the rational structure of tea ware function, the rational structure of tea ware humanistic thought, the rational structure of tea ware experience and the rational structure of tea ware aesthetic image. From these four aspects, the influence of the rational structure of tea ware modeling will be improved steadily [7]. The basic function of tea ware is to meet all tea drinking needs of users. The main tea ware, auxiliary tea ware, water preparation ware and tea preparation ware are the main components of the functional rational structure of tea ware. According to the rational structure of humanistic thought of tea wares, tea wares need to show the modeling design thought of "people-oriented" and reflect the deep humanistic care. The experiential rational structure of tea ware means that when drinkers use tea ware, 
the texture and appearance of tea ware modeling will give people a more comfortable use experience. Tea ware modeling will guide tea drinkers to carry out specific tea drinking practice, and produce an understanding, interest and emotional resonance of tea culture [8]. The rational structure of the aesthetic image of tea ware needs to be related to the color, shape and material of the tea ware itself. For example, depicting ancient Chinese landscape paintings on ceramic tea ware can instantly improve the aesthetic image of tea ware, bring users higher spiritual enjoyment, and make people, nature and tea drinking reach the unity [9]. In addition, it is suggested to add some innovative modern popular elements under the influence of rational structure, so as to make tea ware modeling more applicable to the times.

\subsection{Improving Cultural Connation of Modern Tea Ware Modeling}

China's tea culture is a compound culture involving many fields such as people, thought, etiquette and morality. With the integration of compound culture in these fields into the design of modern tea ware modeling, the cultural and ideological connotation of modern tea ware modeling will be enhanced. In the era of world integration, the cultures of different countries began to develop in China. Foreign cultures with mixed advantages and disadvantages do have a certain impact on the ideology and culture of the new generation of young people [10]. In order to establish the confidence of Chinese culture and carry forward the charm of Chinese traditional culture, it is also necessary to take modern tea ware as the cultural publicity carrier, so that the modeling of modern tea ware can present the ancient and modern Chinese cultural thought with a long history. In the context of the integration of tea and culture, the modeling of modern tea ware should reflect the ideas of various cultural factions, such as the etiquette of Confucianism, the nature of Taoism, the karma of Buddhism, or have a style of their own, or interact with each other harmoniously. However, tea drinkers can eliminate the ideological and cultural differences brought by various cultural factions and feel the breadth and depth of Chinese tea culture [11]. Secondly, the modeling of modern tea ware needs to be combined with Chinese poetry, calligraphy and painting. A more direct design method is to depict these cultural elements on the surface of modern tea ware, so that users have to pay attention to the content depicted in the process of drinking tea. At the same time, more Chinese culture lovers at home and abroad love Chinese tea culture, achieving the cultural export of tea culture in disguise. Finally, modern tea ware modeling needs to show a sense of cultural artistic conception. Jingdezhen porcelain Yi ceramic are the representatives of the sense of cultural artistic conception. When people see blue and white porcelain and purple clay pot, they will be convinced by the cultural connotation of tea ware modeling, which is the mapping attribute of cultural thought itself.

\subsection{Enhancing the Multi-Applicability of the Aesthetics and Techniques of Modern Tea Ware Modeling}

Modern tea ware is not only a practical product but also a handicraft for people. Therefore, to enhance the value of modern tea ware modeling, it is necessary to increase the multiple applicability of modern tea ware modeling art and techniques. Tea ware itself is the product of the integration of spiritual and material needs. With the continuous improvement of Chinese people's living standards, people's positive longing for a better life can be achieved with tea culture [12]. The multiple applicability of aesthetics and techniques means that the aesthetic and artistic value of tea wares and techniques of tea wares have multi-aspect and three-dimensional practical application. In terms of tea ware technology, the modeling of modern tea ware needs to meet the functional material needs and comfort material needs of users. Users can fully feel the convenience brought by the tea ware itself in the process of cooking and drinking tea. The affirmation of users is the highest expression of the material value of tea ware. Tea ware modeling does have a certain impact on users' comfort experience, but it has a greater impact on aesthetic value. Modern tea ware modeling design is reflected in three aspects: shape, color and content. With the support of modern technology, tea ware modeling design will be more stable and coordinated. For example, with the use of electric stove and steam stove, the firing time of tea ware will be greatly shortened. At the same time, it can also burn different colors of glaze according to the needs of designers, so as to better meet the tea drinking needs of modern people [13]. It can be seen that the multi applicability of aesthetics and techniques of tea ware modeling is an inevitable demand of modern tea production. Only by meeting this demand can we create a sustainable tea production market. 


\section{INNOVATIVE DESIGN DIRECTION OF MODERN TEA WARE MODELING}

\subsection{Adding Popular Elements in Modern Tea Ware Modeling}

The innovative design of tea ware modeling does not mean that it is necessary to create a brandnew tea ware style or brand. To integrate the popular factors loved by people of different ages in modern society is an innovative design. Considering the popularity of tea ware modeling, the tea ware modeling itself has certain audiences. For example, the graphite lazy automatic KungFu tea set, which is popular among young people, is a typical example. The classical and simple appearance style and high-quality filter anti-scald design are the representatives of the modeling design of minimalist tea sets, which is very suitable for young people with fast pace of life and great mental pressure. Of course, those unique modern tea ware modelings are of use value and collection value [14]. Chen Jixiao, who lives in the south of the Yangtze River, used the hot spot of "the largest moon" to design a set of "variable glazed moon tea ware". With the combination of soft moonlight and certain ambient temperature conditions, there is colorful tea ware halo. His works are the leaders in the modeling of modern tea ware in terms of appearance and aesthetic experience. But what equally important is to identify a standard of adding the popular elements of modern tea models. Tea culture is a product of the changing times, but the key to keeping pace with the times is to integrate the essence of ancient China's tea modeling design with modern elements. Traditional tea culture, modern design power and manufacturing technology are the important ways to create the best modern tea ware modeling.

\subsection{Innovating the High-quality Modeling of Traditional Tea Ware}

The great success of the development path with Chinese characteristics is not reproducible, but those classic ancient Chinese tea ware modelings are highly reproducible. Those high-quality tea ware modelings are still active in the external economic market of tea ware. The reason why tea ware modelings can still spread under the change of times is that they have some high-quality traditional tea ware modeling elements. However, not all traditional tea modeling elements can adapt to the current era. Therefore, designers need to closely follow the trend of tea ware modeling and "optimize" some traditional tea ware modeling [15]. Yuxiang teapot is a popular tea ware of the ruling class in the late Qing Dynasty. It is small, with low center of gravity, beautiful radian and simple color. The imitated Yuxiang teapot on the market is a successful model for tea ware modeling optimization. In order to make the modeling of Yuxiang teapot more characteristic of the times, the designer added jade dragon-shaped elements to the mouth and ears of tea ware, and depicted Chairman Mao Zedong's classic quotations on the tea ware, so that it is of a higher flavor of the times, collection and practical value. In terms of color, the Yuxiang teapot uses high-quality purple sand, while the imitated Yuxiang teapot uses Yixing purple sand, which essentially reduces the purchase cost of the imitated Yuxiang teapot and increases the market sales of the imitated Yuxiang teapot [16]. From the successful experience of imitated Yuxiang teapot, the high-quality modeling in the innovation of traditional tea ware modeling still needs to be modernized from three aspects: modeling, color and content. And then, it can not only ensure that the elements of traditional tea ware are not lost, but also highlight its modern tea ware modeling charm.

\subsection{Introducing the Geological Aesthetic Thought of Modern Tea Ware Modeling}

The vast Chinese land makes tea modeling more broad. The introduction of geological aesthetics of modern tea ware modeling can make tea ware modeling realize the balance of tea culture and science and technology in the era of network big data. Different geological aesthetic elements should be combined with tea ware modelings. For example, people in northeast China like to drink scented tea, and some modeling elements related to flowers, birds and mountains should be added to the tea ware modeling market in northeast China; people in Tibetan areas on the plateau like to drink butter tea, and some unique Tibetan elements should be added to the tea ware modeling market in Tibetan areas, such as Sutra tube, Potala Palace, etc. [17]. To introduce the geological aesthetic thought of tea ware modeling, it is suggested to select the unique scenery and cultural materials of the region, which can also enable users to have emotional resonance when drinking tea. Then, these tea ware materials are sorted out to integrate with the overall style of tea ware appearance, so as to lay a more positive emotional tone of tea ware. Finally, 
some geological aesthetic implications and modern geological popular elements are added to the modeling of tea ware. However, at the same time, it should be noted that when introducing the geological aesthetic elements of modern tea ware modeling, it is necessary to follow the development idea of great openness and integration, and the modern tea ware modeling will not be limited by regional factors. For example, some KMT-themed modeling elements are added to some tea wares sold in Taiwan, and they have strong Taiwan characteristics. However, when selling in the mainland, the sales market will be limited because of these address aesthetic elements, which is the socalled concept of "getting more kicks than halfpence".

\section{INNOVATIVE PRACTICE PATH OF MODERN TEA WARE MODELING}

\subsection{Innovative and Minimalist Modern Tea Ware Modeling}

Innovative and minimalist modern tea ware modeling has been popular since the 1970s. The concept of "doctrine being simple and easy" is also consistent with the practice of tea culture. Simple modeling, simple color and convenient operation constitute the whole of minimalist style. It is refreshing for tea lovers who have been pursuing beautiful tea ware modeling for a long time and have aesthetic fatigue. However, it should be noted that the minimalist tea ware pursues minimalist but not simplicity. Besides, it does not lack any of the elements contained in modern tea ware modeling, such as material, color, rational structure, aesthetic value, cultural heritage and so on. All unnecessary modeling limitations of tea ware are removed, leaving absolute functional and aesthetic value [18]. However, some innovative modern elements need to be added in the modeling of modern tea wares. The "Zen" of Buddhism and the "simplicity" of Taoism are the representatives, and they are extended to be "peaceful", "less orectic" and "natural". At the same time, the innovative and minimalist modern tea ware modeling also needs to follow some hard modeling rules. The first is to follow the rule of "subtraction" in tea ware modeling design. In addition to some necessary functional requirements, other designs are not allowed. Then, it is to reflect the minimalist thought of "returning to nature", so that users can actively practice the original intention of drinking tea.
Finally, it is required to show a simple rational structure of modern tea ware modeling. The public materials and one or two basic colors are the embodiment of minimalist style.

\subsection{Innovative and Environment-friendly Modern Tea Ware Modeling}

From the construction of "Green China" to the construction of "low-carbon city" and then to the construction of "rural eco-tourism", green environmental protection has become an era proposition. As a "tea drinking country", China naturally needs to be the practitioner of innovative and environment-friendly modern tea ware modeling under the promotion of a sense of social responsibility. China's production and manufacturing industry of modern tea ware is indeed developed. The main raw materials are still ceramics, glass, bamboo and metal. The green production and manufacturing of tea ware also needs to adhere to the rules of "low consumption", "being renewable", "recycling" and "being degradable and pollution-free". Glass and ceramic tea wares belong to non-renewable resources and have a high damage rate. Therefore, metal materials and bamboo materials should be preferred for the modeling of innovative and environment-friendly tea wares, but the best is still bamboo wood materials because of its strong renewable ability and high degradable benefits. The environmentfriendly bamboo tea set independently developed and designed by Dong Changwei is a representative work of innovative and environment-friendly tea sets in recent years. The outer wall is the green of bamboo itself and the inner wall is white. Some endangered animals and plants in China and their profiles are depicted on the outer wall, and some moving publicity slogans are engraved below, so that tea drinkers can inadvertently see these environmental protection ideas. The material of bamboo and proper modeling design inhibit the waste of tea ware modeling materials to a certain extent. Even if the tea ware is accidentally damaged, it will not cause environmental pollution due to discarding. There are many innovative tea ware modeling design works, achieving good sales in China. The state also strongly supports this environment-friendly tea ware works that show the idea of sustainable development. 


\subsection{Innovative and Retro Modern Tea Ware Modeling}

Looking at the tea ware modeling in modern society, it is found that it is similar to the tea ware modeling in the Ming Dynasty, that is, the modern tea ware modeling shows the antiquities, and the practice path of designing modern tea ware modeling still needs to include the innovative and retro modern tea ware modeling, which aims to maintain the original ecology of tea culture. This original ecological retro tea ware modeling can reduce people's life rhythm and life pressure to a certain extent. Drinking tea in a comfortable state can better restore the fun of "unifying the human and nature". Innovative and retro modern tea ware modeling still takes flowers and birds, trees and mountains and rivers as the basic theme. Among them, the representative work is the retro ginkgo teapot. Taking dark red color as the background color of tea ware, the outer wall is painted with ginkgo tree patterns. The modeling is extremely irregular. From a distance, it looks like a ginkgo gall cut and abandoned for a long time, which truly and naturally restores the original plant scene and also secretly creates a tea drinking atmosphere in which people live in harmony with nature. In fact, foreign tea ware designers also have some excellent retro original ecological tea ware works. For example, the Chinese weiqi tea ware designed by Antralph is unique. The tea ware itself is a chessboard shape. The two-color matching of wood material, together with some black chess pieces and white chess pieces, makes the two sides drink tea just like playing chess, which creates a novel idea of tea drinking and a positive atmosphere.

\subsection{Innovative, Indifferent and Comfortable Modern Tea Ware Modeling}

The original intention of tea drinking is to make tea drinkers calm and comfortable, relaxed and happy. At the same time, tea drinking is also the best decompression way for people living in modern society. Therefore, the innovative, indifferent and comfortable modern tea ware modeling is also an inevitable product of the development of the times. This concept of innovative modern tea ware modeling is similar to that of the hot "slow city construction", which constantly expands the spiritual pleasure experience on the basis of "people-oriented" principle. Some people also call this modern tea ware modeling as "slow series" of tea ware modelings. With this slow and peaceful state of mind, tea drinkers can realize the peak of tea culture. The "moon tea ware" designed by the theme tea ware modeling design studio in Seoul, South Korea perfectly interprets the design concept of innovative, indifferent and comfortable modern tea ware modeling. Firstly, the "moon tea ware" is made of ceramic material, which has the properties of hard-working and wearresistant material. It has the dark black tea ware color, and the wide body and narrow mouth makes the rhythm of making and pouring tea naturally slow down. The tea cup is separated by a dominant arc, and the bottom of the tea cup is engraved with a landscape painting. When it is full of the tea, people can see the milky white full moon. With the continuous lowering of the depth of the tea, the full moon will slowly become a half moon and a curved moon, and the beautiful scenery at the bottom of the tea cup will slowly emerge, showing the natural beauty brought by the slow rhythm. Finally, the "moon tea ware" will also show tea drinkers a spiritual aftertaste feast. Life is like the process of drinking tea. The moon has the states of beings full and curved, and it is true for life.

\section{CONCLUSION}

As an old Chinese saying goes, "life is nothing but firewood, rice, oil, salt, soy sauce, inegar and tea". Tea, as a necessity of everyone's life, has formed a relatively rich tea culture. As an important content reflecting the cultural heritage and spiritual thought of tea, the modeling design of tea ware has always been the main research content of designers in ancient and modern times. With the continuous advancement of national development strategies such as sustainable development, aesthetic education and moral education, the modeling design of modern tea ware is also undergoing innovation. Starting from the positive connotation of modern tea ware modeling in the education 4.0 era and the development history of tea ware modeling, this paper expounds in detail the design principles and directions of modern tea ware modeling from three aspects: cultural connotation, rational structure and multiple applicability, and lists four types of modern tea ware modeling design concepts, such as minimalist style, environmentfriendly style, indifferent and comfortable style and retro style and representative works, so as to provide theoretical reference for the development of modern tea ware modeling. However, due to the limitation of knowledge level, the author still does not fully elaborate the feasibility analysis principle of modern tea ware modeling. In the future study 
and research, this research direction will be taken as the next topic of tea modeling research. And this paper studies the subject from the three directions of economic development, technical development and theoretical development, hoping to help the development of tea ware modeling.

\section{AUTHORS' CONTRIBUTIONS}

This paper is independently completed by Yueming He.

\section{REFERENCES}

[1] Zhang Qi. From "Creation" to "Appreciation" - The value of Cai Yuanpei's "aesthetic education" thought in the contemporary creative design of tea ware $[\mathrm{J}]$. Art Life Journal of Fuzhou University (Art Edition), 2020( 04): 33-40. (in Chinese)

[2] Zhang Jiaye. Innovative design of tea set based on modern product design concepts [D]. Qilu University of Technology, 2020: 22-25. (in Chinese)

[3] Pan Litao. Research on design method of tea sets using multi-dimensional image scale [D]. Zhejiang Agriculture and Forestry University, 2020: 11-15. (in Chinese)

[4] Cen Yining. Research on the design of ceramic tea ware in modern Zen space [D]. South China University of Technology, 2020: 16-17. (in Chinese)

[5] Fan Qiancheng. Analysis of the design of tea ware art derivatives under the modern industrial form [J]. Tea in Fujian, 2018, 40(11): 374. (in Chinese)

[6] Cai Bowen, Liu Wenhai. Study on the application of the aesthetic characteristics of Cizhou kilns in the Song Dynasty in the design of contemporary tea sets [J]. Industrial Design, 2018(10): 68-70. (in Chinese)

[7] Huang Zeping. Discussion on the relationship between ceramic tea ware and Xinyang tea inheritance and development based on China's tea culture [J]. Policy Research \& Exploration (Part 2), 2018(07): 91-92. (in Chinese)

[8] Huang Liujing. Study on the household utensils in the ethnic cultural context of the Wa and Dai nationalities [D]. Yunnan Arts University, 2018: 22-23. (in Chinese)
[9] Xing Lichan. Research on the Context Deduction and Narrative Expression of Zen Tea Culture in the Design of Cultural and Creative Products [D]. Anhui Polytechnic University, 2018: 13-19. (in Chinese)

[10] Tian Huiying. Discussion on innovative design methods of modern tea sets $[\mathrm{J}]$. Tea in Fujian, 2018, 40(02): 170-171. (in Chinese)

[11] Ren Dongfang. Research on the aesthetic design of ceramic teaware under the traditional cultural concept $[\mathrm{J}]$. Tea in Fujian, 2017, 39(05): 140-141. (in Chinese)

[12] Zhang Jinhui. Research on Congou Culture and Teaware Design in Chaoshan Area, Guangdong [D]. Hubei University of Technology, 2017: 26-28. (in Chinese)

[13] Wang Wensheng. On the design of tea utensils and the aesthetic psychology of consumers [J]. Tea in Fujian, 2017, 38(11): 170-171. (in Chinese)

[14] Tang Yiling. Research on the design and development of ceramic teaware in Jingdezhen [J]. Tea in Fujian, 2017, 38(11): 161-162. (in Chinese)

[15] He Jing. Research on the innovative design method of modern tea sets $[\mathrm{J}]$. Journal of Jingdezhen University, 2017, 31(03): 76-79. (in Chinese)

[16] Tong Jihong. Research on the application of Zen culture in the design of ceramic teaware [D]. Jingdezhen University, 2019: 23-25. (in Chinese)

[17] Cheng Liqin. On the art and design of Jingdezhen handmade tea ware against the background of tea culture [J]. Tea in Fujian, 2017, 38(01): 164-165. (in Chinese)

[18] Chen Bao. On the design art of Congou tea set in Chaozhou [D]. Jingdezhen University, 2017: 22-25. (in Chinese) 